\title{
Desafios e perspectivas à editoração da Revista Psicologia: Ciência e Profissão
}

A difusão do conhecimento, nas diferentes áreas da ciência, implica desafios permanentes, tendo em vista a dinâmica dos processos culturais, de inovação e geração de produtos científicos. A produção do conhecimento, divulgada em diferentes veículos comunicacionais, reflete tensões, consensos e divergências, próprios do avanço da ciência, salientes à necessidade de interferir e contribuir na dinâmica do processo civilizatório. Nesse sentido, o movimento da produção do conhecimento científico, e sua difusão, devem se orientar não somente pelo o que se conhece, mas, principalmente, por aquilo que se pode conhecer (Sagan, 1999). É esse, na verdade, o sentido de fazer ciência: orientar-se para um certo desconhecido, identificando obstáculos, expectando desafios e oportunidades.

Os periódicos científicos são, nesse sentido, aparatos sociais e tecnológicos de observação, sistematização e difusão do movimento da ciência, em seus diferentes pontos de inflexão. Por isso, ao procurarem espelhar esse movimento, os periódicos científicos também enfrentam obstáculos em manter-se atualizados ao fluxo da produção do conhecimento, o que implica em lidar com os desafios e as oportunidades de gerenciamento do processo de avaliação de pares e divulgação da produção científica na comunidade.

A Revista Psicologia: Ciência e Profissão é, reconhecidamente, um periódico de ampla repercussão na comunidade acadêmica e profissional da Psicologia. Nos últimos três anos, foram submetidos 837 artigos e relatos de experiência, com uma média anual de 279 e crescimento anual médio de aproximadamente $25 \%$. Esses dados, que refletem a receptividade da Revista entre os seus interessados, indicam, também, a necessidade do trabalho diligente e cuidadoso na valorização dos artigos recebidos e no seu devido processo de avaliação.

A Revista Psicologia: Ciência e Profissão pretende continuar trilhando o seu caminho de oferecer à comunidade um periódico que expresse a diversidade da produção científica em Psicologia e a qualidade dos processos de intervenção psicológica em diferentes contextos. O processo de seleção dos textos continua mantendo a tradição da revista, que publica textos originais, e que busca difundir o conhecimento psicológico em suas mais diversas facetas.

O crescimento e diversificação da produção do conhecimento em Psicologia, o acentuado número de trabalhos submetidos à Revista e a necessidade cada vez mais premente de reduzir o tempo entre a submissão, aprovação e publicação dos artigos, têm exigido, porém, uma atenção acentuada por parte de seu corpo técnico-editorial, face ao impacto que essas exigências produzem no gerenciamento da editoração da Revista.

Em vista disso, está em curso um processo de capacitação interna dos profissionais envolvidos na produção da Revista, visando implementar mudanças voltadas ao aprimoramento dos critérios de submissão, avaliação inicial, fluxo de tramitação e avaliação dos artigos por meio de consultores ad hoc, assim como no aprimoramento da qualidade da comunicação entre usuários e corpo técnico-editorial da Revista. Pretende-se, com esse processo, implementar e validar boas práticas de gerenciamento de editoração que mantenham e induzam a submissão 
e publicação de artigos científicos de boa qualidade, que reflitam os desafios teóricos-metodológicos da produção científica e processos de intervenção psicológica no Brasil e no mundo.

Todo esse processo busca alinhar necessidades de aperfeiçoamento na editoração de periódicos no Brasil, gerados pelos debates atuais sobre a dinâmica e os desafios da internacionalização da produção científica e a busca por melhorias na produção científica brasileira, sinalizados, de forma enfática, pelos argumentos promovidos pela SciELO. Esses argumentos salientam a necessidade de mudanças no processo de editoração de periódicos científicos no Brasil, com o estabelecimento de novos critérios para admissão e permanência de periódicos na plataforma SciELO, visando contemplar avanços no processo de profissionalização da editoração, sustentação econômica e divulgação internacional dos periódicos científicos brasileiros. A expectativa é gerar maior exposição e índices de impacto da produção científica publicada em periódicos nacionais, ou seja, um maior nível de citações da produção autoral indexada.

Há um conjunto de novos critérios, estabelecidos desde o final do ano de 2014, em documento produzido pela SciELO, voltados à manutenção da indexação de periódicos em sua plataforma, que incluem, dentre outros, o processo de editoração on-line, com automatização de procedimentos em diferentes formatos, dispositivos eletrônicos e de verificação de elementos textuais/bibliográficos, critérios mínimos de participação de editores associados, revisores e autores estrangeiros, quantidade mínima de artigos a serem publicados anualmente e aqueles em língua inglesa.

Todos esses esforços envolvem não somente o aprimoramento do gerenciamento técnico e tecnológico do processo de produção da revista, mas também a participação cada vez mais eficiente e colaborativa entre equipe técnica-editorial, autores e avaliadores. O produto principal, a Revista Psicologia: Ciência e Profissão, deve resultar de uma combinação positiva entre planejamento de ações a curto, médio e longo prazo, aprimoramento técnico-científico e tecnológico do processo de gerenciamento da produção editorial e dedicação dos envolvidos, a fim de oferecer um produto intelectual científico e socialmente relevante à comunidade.

\section{Roberto Moraes Cruz}

Universidade Federal de Santa Catarina

Editor 
Sagan, C. (1999). O mundo assombrado pelos demônios: A ciência vista como uma vela no escuro. São Paulo, SP: Companhia das Letras. 